\section{The Pineal Gland: Anatomical, Clinical and Neurobiochemical Profiles, Between Hypotheses of the Past, Certainties of the Present and Future Perspectives}

Keywords: Psychology; Neuroscience; Psychoneuroendocrinoimmunological system; Pineal gland; Melatonin; Serotonin; Circadian rhythm; Sleep; Sleep-wake; Sleep disorders; Neurodegenerative diseases; Schizophrenia; Psychotic diseases

\begin{abstract}
Starting from the anatomical analysis of the pineal gland, the study focuses on the examination of clinical and neurobiochemical profiles, especially concerning melatonin, a hormone involved in the psychoneuroendocrinoimmunological system, shifting attention to past hypotheses, present certainties and future prospects medical research on this mysterious gland.
\end{abstract}

\section{The Pineal Gland: Anatomicals and Neurobiochemicals Profiles}

The pineal gland (or epiphysis) is an endocrine gland of the vertebrate brain. It protrudes at the posterior end of the third ventricle and belongs to the epitalamus. It is connected by some equal and symmetrical nerve bundles (epiphyseal peduncles) to the surrounding nervous parts. It is notoriously known for the function of its cells, called pinealocytes, in the production of melatonin, a neurotransmitter that regulates the sleep-wake circadian rhythm.

The gland has been known since the ancient era and is characterized by its calcification in mature age. Its dimensions are about one centimeter long by half wide, and its weight is around half a gram [1-3].

The epiphysis originates from the ectoderm and from a phylogenetic point of view from photoreceptor cells sensitive to light and capable of generating an electrical impulse. This characteristic was lost in mammals, therefore these organisms developed during the evolution an intricate nervous system that allowed the impulses coming from the ocular retinal receptors to reach the epiphysis.

The epiphyseal parenchyma is organized in cord structures. Inside there are two types of cells: parenchymal or pinealocyte cells and interstitial cells, as shown in the diagram below:

\section{Journal of}

Neurology and Psychology

\section{Giulio Perrotta*}

Department of Criminal and Investigative Psychology Studies, University of Federiciana, Cosenza, Italy

*Address for Correspondence

Giulio Perrotta, Department of Criminal and Investigative Psychology Studies, University of Federiciana, Cosenza, Italy, Phone: (+39) 349 2108 872; E-mail: giuliosr1984@hotmail.it

Submission: May 13, 2019

Accepted: June 10, 2019

Published: June 12, 2019

Copyright: () 2019 Giulio Perrotta. This is an open access article distributed under the Creative Commons Attribution License, which permits unrestricted use, distribution, and reproduction in any medium, provided the original work is properly cited.

The epiphysis belongs to the family of circum ventricular organs (therefore it does not have a blood-brain barrier). Nevertheless, the pineal gland is a highly vascularized organ. In particular, the arterial blood comes through the posterior choroidal arteries, while the venous one flows into the internal cervical veins. The epiphysis receives photosensory information from the eye from indirect neuronal channels. The light perceived by the retinal ganglion cells is transformed into an electrical impulse and transferred to the Suprachiasmatic Nucleus (SCN) through the Retinoipotalamic beam (RTH). Later, the impulse passes to the lateral hypothalamus; from here to the brain stem through the medial prosencephalic bundle and to the intermediolateral column of the cervical portion of the spinal cord. At this point the impulse reaches the upper cervical ganglion and hence the tentorium of the cerebellum. Finally through the epiphyseal nerves it reaches the epiphysis. The pineal gland is in close contact with the cerebrospinal fluid. To explain the presence of pineal hormones in plasma and urine a pineal secretion was also hypothesized at the vascular level. The main site of action of melatonin is in the brain, but it can also act directly on the pituitary gland and on other peripheral organs. Also the liquor, blood and urinary levels of melatonin vary in relation to the environmental brightness with peaks in the hours in which the latter is poor.

From a neurobiochemical point of view, as already stated, the pineal gland produces melatonin, a hormone isolated for the first time in 1958 by Aaron Lerner and produced by pinealocytes starting from the neurotransmitter serotonin (5-hydroxy-tryptamine) for $\mathrm{N}$-acetylation and oxy-methylation, by virtue of the fact that these cells contain the enzyme Hydroxy- Indole-Oxy Methyl Transferase (HIOMT), epiphysis marker enzyme. It acts in the circadian rhythm of sleep and has powerful antioxidant effects: melatonin is synthesized in the absence of light from the pineal gland; shortly after the onset of

\begin{tabular}{|c|c|c|}
\hline Type of cells & $\begin{array}{c}\text { Description } \\
\text { Parenchymal cells }\end{array}$ & $\begin{array}{r}\text { Also called pinealocytes, they are deputed to the synthesis of melatonin. They are of neuroepithelial origin and have an epithelial } \\
\text { aspect. The silver impregnation method highlights the basophilia of the cytoplasm and the dendritic aspect (with thin and long } \\
\text { extensions that end near the capillaries). Furthermore the pinealocytes produce a protein matrix that undergoes calcification. In fact, } \\
\text { even after puberty there are calcareous concretions called acervules. }\end{array}$ \\
\hline Interstitial cells & $\begin{array}{r}\text { They constitute the stromal tax rate. They are modified glial elements, also of neuroepithelial origin. Phagocytes are present, } \\
\text { immersed between the interstitial cells and near the capillaries that supply the epiphysis. These play the role of APC. }\end{array}$ \\
\hline
\end{tabular}


darkness, its concentrations in the blood increase rapidly and reach the maximum between 2 and 4 am and then gradually decrease as the morning approaches. Exposure to light (especially at the blue wavelength between 460 and $480 \mathrm{~nm}$ ) inhibits the production of melatonin in a dose-dependent manner. It is therefore used for the short-term treatment of insomnia over 55 years of age. The side effects of melatonin are not null, although the contrary belief is widespread: over the years, various professional bodybuilders and various sports information magazines have affirmed the possibility, with the support of some scientific studies, that daily doses between $0.5 \mathrm{mg}$ and $3 \mathrm{mg}$, taken 30-60 minutes before training, increase the levels of growth hormone, without giving side effects, which are usually recognized in irritability and drowsiness. Melatonin decreases the release of GnRH: for this reason the synthesis of testosterone and therefore libido decreases. More precisely, it inhibits the secretion of the luteinizing hormone, which stimulates the male endocrine activity of the interstitial cells of the testis with testosterone and sperm production, and in the female ovulation and conversion of the ovarian follicle into the corpus luteum. Taken for prolonged periods, melatonin can have a depressive effect in predisposed subjects; furthermore, it can inhibit ovulation precisely because of the suppression of the $\mathrm{GnRH}$ release it causes.

\section{The Pineal Gland: Clinical Profile}

As already stated, if the physical eye, with the retina, perceives light and gives the body a rational type of information, the pineal incorporates the condition of light and darkness modulating it so as to give the body what it needs, to whose light is configured as the basic principle of life. In fact the first principle of the state of health is the ability to differentiate light from darkness. It is therefore responsible for the circadian rhythm, that is the cycles that are performed in about 24 hours on the basis of the main cosmological rhythm, that of light and dark alternation, which occurs approximately in 24 hours (12 for the day/wake, 12 for night/sleep).

The pineal gland produces many substances, more than three hundred, when it is healthy and in full activity. Among these, also a natural hallucinogenic substance, Dimethyltryptamine (DMT), called by scientists, and not surprisingly, "the molecule of God or spirituality", because it is the means that allows access to the invisible spiritual world and astral travel, that is, out-of-body experiences, which are what we all do when we go to sleep. It represents the means by which the soul can know itself and develop itself, but to do so it needs a material basis in the world in which it has chosen to incarnate. Some studies have shown that among the substances secreted by the pineal gland there is pineal in or pinoline, a neurotransmitter that activates the REM phases of sleep and allows the attainment of very high states of consciousness, giving rise to lucid dreams (a term coined by psychiatrist Frederick Van Eden to indicate an experience during which one is aware of dreaming).

Currently, other substances isolated from the epiphysis are being studied: arginine vasotocin, the epiphyseal antigonadotropin peptide and a gonadotropin-releasing factor other than hypothalamic.

Inside there are micro-crystals of hydroxyapatite $\mathrm{Ca}_{5}\left(\mathrm{PO}_{4}\right)_{3}$ $(\mathrm{OH})$ impregnated with phosphoric calcium and manganese salts similar to sand grains the size of $2 \mathrm{~mm}$ which, in the presence of ultraviolet light, produce a celestial white fluorescence. To the group $(\mathrm{OH})$, one can also attack Fluorine $(\mathrm{F})$, aluminum residue and Chlorine $(\mathrm{Cl})$ producing crystals composed of phosphates and calcium carbonate, which are bad for the pineal, because they calcify it gradually transforming it into a pebble. Calcification is the basis of its malfunction, but it can also be affected by more or less serious pathologies. Among the negative factors: sleep/wake cycles not respected: night work alters the functionality of the pineal; use of toothpastes, water, tranquilizers and antidepressants that contain fluorine; smoking and drinking alcohol exaggeratedly; stress: worries stimulate the production of corticosteroids and catecholamines and drastically lower melatonin production.

The epiphysis, contrary to the other endocrine glands, is not under the control of release or inhibition factors coming from the blood circulation, but under that of the nervous system, in particular of its sympathetic section; it can therefore be considered as a neuroendocrine transducer that converts nerve impulses into changes in hormone secretion.

The causes of the calcification of the pineal gland are not completely identified, even if it appears to be identified in the normal maturation of the adult age of the person, excessive intake of fluoride and electromagnetic fields.

Another problem linked to calcification is the degenerative process of the pineal gland. Tumors of the pineal region are formed in or near the pineal gland. Most of these cancers are germinal cells, pineal cells (pinealocytes) or glial cells. The tumors of the pineal region are divided into $[4,5]$ :

a) Tumors originating from germ cells, including the pluripotent cells that we find at the embryonic level (teratomas, germinomas, embryonic carcinomas, etc.);

b) Tumors originated from the pineal cells (pinealocitomas, pinealoblastomas etc.);

c) Tumors arising from glial cells (astrocytomas etc.);

d) Tumors originating from pineal cells are distinguished on the basis of aggressiveness: pinealocitomas are benign tumors (30\%), pinealoblastomas are malignant $(50 \%)$ and $20 \%$ are mixed tumors. These types of tumors can appear in adolescence, but also in middle age.

The symptoms that can arise in case of tumors of the pineal region are:

a) Increase in intracranial pressure, as an obstacle to the intracranial circulation of the liquordysregulation of the reproductive system, due to the effects that the hormones produced by the pineal have especially against the sex hormones;

b) Headache, nausea and vomiting;

c) Alteration of ocular motility which also includes Parinaud's Syndrome (inability to look upwards);

d) Motor disorders;

e) Endocrine disorders (more rare). 
Citation: Giulio Perrotta. The Pineal Gland: Anatomical, Clinical and Neurobiochemical Profiles, Between Hypotheses of the Past, Certainties of the Present and Future Perspectives. J Neurol Psychol. 2019; 7(1): 5.

\section{The Role of the Pineal Gland in the Hypotheses of The Past}

The first description and the first speculations about the pineal gland are found in the voluminous writings of Galen, who treated the pineal gland in his "De usu partium" [6,7]. In it, Galen explains that the gland owes its name to its similarity, in shape and size, to a pine nut. He called it gland because of its appearance and equated its function with that of the other glands of the body, which in its conception served mainly as a support for blood vessels. Galen was firmly opposed to a widespread conception according to which the pineal gland regulates the flow of spirit, a vaporous substance which was thought to be full of cerebral ventricles. Galen rejected this idea primarily because the pineal gland is attached to the outside of the brain and cannot move autonomously and, therefore, could not have directed the flow of spirit into the ventricles of the brain. In fact, he argued that the cerebellar vermis (the middle part of the cerebellum) was more qualified to perform this function.

Later the theories of Galen were taken up to expand or sometimes modify them. Nemesio di Emesa, for example, expanded them by adding the idea of ventricular localization, according to which each part of the brain corresponds to a different faculty: the imagination of the anterior ventricle, the reason to the ventricle and the memory to the rear. This theory remained in vogue until the mid-sixteenth century.

In a treatise called On the Difference between Spirit and Soul Qusta ibn Luqa combined Nemesio's theories and Galen's conception of the regulation of the spirit through the cerebellar vermis. In this regard he applied his theory to justify the flow of consciousness: according to his hypotheses, those who wanted to remember looked up so that this vermiform appendix opened the passage and allowed the flow of memory. Those who wanted to think, on the contrary, looked down so that the passage was closed and the spirit of reason was not corrupted by that of memory. The Treaty of Qusta greatly influenced medieval European scholasticism.

In many medieval texts, including those of Mondino dei Liuzzi, this vermiform appendix was given the term pinea, resulting in some ambiguity, as it could refer to both the cerebellar vermis and the pineal gland.

At the beginning of the $16^{\text {th }}$ century anatomy made progress and a first more scientific reading of the pineal gland was made public: Niccolò Massa discovered that cerebral ventricles are not filled with spirit but with fluid (cerebrospinal fluid). Moreover, Andrea Vesalius rejected all theories concerning ventricular localization and those according to which the pineal gland or the cerebellar vermis regulate the flow of spirit, dissolving the ambiguity created in the Middle Ages.

Descartes was very interested in human anatomy and physiology. He deals largely with the pineal gland, especially in the treatise De homine and in his last book. The passions of the soul. The point of view of "De homine" is purely mechanistic: in fact, Descartes sees the body as nothing more than a machine whose functions can be reduced to the physical principles of classical mechanics. Inspirers of the Iatromechanical medical doctrine: within this machine the pineal gland plays a central role, as it is involved in the perception, imagination, memory and causality of bodily movements. Many of the basic anatomical and physiological assumptions of Descartes were totally wrong, not only for our age, but also in light of what was already known in his time: first Descartes thought that the pineal gland was suspended in the midst of the ventricles, while it is not, as already pointed out by Galen; animal spirits ", carried by small arteries, while already Galen confirmed that surrounding the gland there were more veins than arteries; he described these animal spirits as a very fine wind, or as a pure and lively flame that swells the ventricles, but Massa had discovered a century before the ventricles are full of liquid and not of spirit. The passions of the soul could be seen as a continuation of the treatise on man: many of the themes discussed in it concerning the pineal gland recur. Descartes deepens more the concept of soul and body, and the role of the pineal gland acquires greater importance from the moment in which it is the principal center of the soul, in which the "res extensa" is joined to the "res cogitans".

In scientific studies of the pineal gland, there was little progress until the second half of the nineteenth century. In 1828, Magendie could still advance the theory that Galen had dismissed. He suggested that it was a valve designed to open and close the cerebral aqueduct. By the end of the nineteenth century, however, the situation began to change. First, several scientists independently launched the hypothesis that the pineal gland was a phylogenetic relic, a vestige of a third dorsal eye. A modified version of this theory is still accepted. Furthermore, scientists began to assume that the pineal gland was an endocrine gland. This theory was completely accepted in the twentieth century: in fact, thanks to scientific and biochemical developments, there is currently a fairly complete knowledge of the functions performed by the epiphysis and its secretions.

\section{The Role of the Pineal Gland in Modern Scientific Research and In Future Perspectives}

$<<(\ldots)$ In 1919, Frederick Tilney and Luther Fiske Warren wrote that the similarities between the structure of the pineal gland and the human eye suggest that the organ is sensitive to light and that it probably has other visual capabilities. (...) In 1995, Dr. Cheryl Craft, president of the Department of Cell Biology and Neurobiology at the University of Southern California, hypothesized that the pineal gland was "the eye of the mind". (...) According to an article based on Dr. Craft's research and published by USC Health and Medicine, "using the tools of molecular biology, the Craft showed that the pineal gland and retina have a large number of genes in common". The article ends by quoting the words of the doctor herself: «Who knows? Perhaps we will solve the big questions about the mind, the matter and the functioning of the universe. Only time can tell us". (...) Looking at previous studies, one can see that Dr. Craft's discoveries are in perfect agreement with what scientists had discovered in the 1950s: the pineal body is able to detect light and produce melatonin. (...) During a 2013 study on the nature of consciousness, a molecule known as DMT (Dimethyltryptamine) was discovered in the pineal bodies of mice. The study was funded in part by the Cottonwood Research Foundation and directed by Dr. Rick Strassman. DMT is also a psychedelic drug and Strassman calls it "the spirit molecule". (...) Dr. Strassman, a researcher at the University of New Mexico, during government-approved clinical research, injected DMT on volunteers and said: "The most interesting result is that high doses of DMT seem 
Citation: Giulio Perrotta. The Pineal Gland: Anatomical, Clinical and Neurobiochemical Profiles, Between Hypotheses of the Past, Certainties of the Present and Future Perspectives. J Neurol Psychol. 2019; 7(1): 5.

ISSN: 2332-3469

to allow the consciousness of volunteers to enter and get out of your body, living different states of existence». (...) According to another theory published by the Journal of Biological Rhytms, the pineal gland "appears to have developed as an indirect system to improve vision". The theory studies melatonin, the pineal hormone that regulates the sleep-wake cycle, and represents the work of David Klein, director of the neuroendocrinology department of the National Institute of Child Health and Human Development (...)>> [8].

Recent research in the biomedical field, especially on melatonin, has shown that:

1) Melatonin is importantly involved in inflammatory processes and cellular apoptosis [9].

2) Exposure to electromagnetic fields decreases the secretion of melatonin [10], which negatively affects cellular processes linked to death, acts on sex hormones and connected glands and interferes with the sleep-wake rhythm [11].

3) Melatonin intervenes in the neurobiological processes involved in anorexic and bulimic disordersand in the predisposition to be subject to these psychophysical pathologies [12].

4) Melatonin is involved with cortisol in the immunomodulatory response [13].

5) Melanin intervenes in the regulation of acidosis in malignant tumor processes [14].

6) Melatonin is a potent inhibitor of ovarian and prostate cancer $[15,16]$.

7) Melatonin has positive effects on blood pressure, reducing hypertension [17].

8) Melatonin, having antioxidant and modulating properties of the circadian rhythm, has positive effects on drug therapy in the presence of schizophrenia and in general in psychotic syndromes $[18,19]$.

9) Melatonin has a positive effect on blood sugar, reducing blood levels and favoring a positive prognosis on insulin therapy in the rats [20].

10) Melatonin, compared to problems related to the central nervous system, seems to be directly involved in the reduction of tissue and nerve lesions, affecting free radicals due to its powerful antioxidant effect. Since endogenous melatonin levels decrease significantly in senility, these results imply that the loss of this antioxidant could contribute to the incidence or severity of some agerelated neurodegenerative diseases [21].

11) Melatonin, precisely because it is related to serum and ionized calcium levels [22], positively intervenes in vertebral disorders and intervertebral degeneration (in chicken) $[23,24]$; also in the cartilaginous problems and curvature of scoliosis $[25,26]$.

12) Melatonin has beneficial effects on respiratory problems linked to obstructive bronchospasm [27].

\section{Conclusion}

Recent studies have then demonstrated the fundamental role of the pineal gland in the psychoneuroendocrinoimmunological system, directly involved precisely because of its ability to secrete over three hundred substances. Among these substances, melatonin appears to be the most studied: it is an endogenous hormone regularly produced by the pineal gland that does not act on the specific target tissue; it reaches all organs and tissues and enters all intracellular structures such as the mitochondria and the nucleus. Melatonin has an important physiological effect on body processes including regulation of blood pressure, circadian rhythms, ovarian function, seasonal reproduction, immune function and bone and spinal disorders, precisely because of its interaction with serum calcium and ionized calcium. Furthermore, high doses of melatonin (up to $50-100 \mathrm{mg} /$ day) are prescribed in neurodegenerative diseases, chemotherapy and congenital immune dysfunctions; however, the dosage above 5-10 $\mathrm{mg}$ must always be prescribed by a specialist doctor, as it has direct effects on human glands, hormones and blood clotting [28]. On the other hand, the role of the pineal gland in extracorporeal experiences and in general in kinetic psychic phenomena - as argued in the past by parapsychological research - has not currently been demonstrated with rigor and scientific method; however, frontier studies are based on alternative hypotheses to investigate the relationship between these arguments and the biological functions of this gland that are not yet fully known.

\section{References}

1. Felten DL, Maida ME, O'Banion MK (2015) Netter's Atlas of Neuroscience, Elsevier - Health Sciences Division ( $3^{\text {rd }}$ Edn).

2. Mai J, Majtanik M, Paxinos G (2015) Atlas of the human brain (4 ${ }^{\text {th }}$ Edn) Academic Press pp: 456.

3. Mtui E, Gruener G, Dockery P (2015) Fitzgerald's clinical neuroanatomy and neuroscience ( $7^{\text {th }}$ Edn). Elsevier pp: 400.

4. Waxman SG (2017) Clinical Neuroanatomy (28 $8^{\text {th }}$ Edn). McGraw-Hil Education pp: 384.

5. Gray F, Duyckaerts C, De Girolami U (2018) Escourolle and poirier's manual of basic neuropathology (6 $\left.6^{\text {th }} \mathrm{Edn}\right)$. Oxford University Press.

6. (2005) Rudolf Steiner, Universo, terra, uomo (world, earth and man, their nature and evolution, so much their reflection in the connection between the proto-myth and the contemptuous culture), Editrice Antroposofica, Milano pp: 107-108.

7. (1822) Karl GottlobKühn (a cura di), ClaudiiGalenii opera omnia, Leipzig, Karl Knobloch.

8. Stanford Encyclopedia of Philosophy (2013) Descartes and the Pineal Gland

9. Tarocco A, Caroccia N, Morciano G, Wieckowski MR, Ancora G, et al. (2019) Cell Death Dis 10: 317.

10. Pfluger DH, Minder CE (1996) Effects of exposure to $16.7 \mathrm{~Hz}$ magnetic fields on urinary 6 -hydroxymelatonin sulfate excretion of Swiss railway workers. J Pineal Res 21: 91-100.

11. Halgamuge MN (2013) Pineal melatonin level disruption in humans due to electromagnetic fields and ICNIRP limits. Radiation Protection Dosimetry 154: 405-416.

12. Liu L, Yi J, Ray WK, Vu LT, Helm RF, et al. (2019) Fasting differentially alters the hypothalamic proteome of chickens from lines with the propensity to be anorexic or obese. Nutr Diabetes 9: 13.

13. Baekelandt S, Mandiki SNM, Kestemont P (2019) Cortisol and melatonin involved in the immune modulation by the light. J Pineal Res 29: e12573.

14. Sonehara NM, Lacerda JZ, Jardim-Perassi BV, de Paula Jr R, MoschettaPinheiro MG et al. (2019) Melatonin regulates tumor aggressiveness under acidosis condition in breast cancer cell lines. Oncol Lett. 17: 1635-1645. 
Citation: Giulio Perrotta. The Pineal Gland: Anatomical, Clinical and Neurobiochemical Profiles, Between Hypotheses of the Past, Certainties of the Present and Future Perspectives. J Neurol Psychol. 2019; 7(1): 5.

15. Zare H, Shafabakhsh R, Reiter RJ, Asemi Z (2019) Melatonin is a potential inhibitor of ovarian cancer: molecular aspects. J Ovarian Res 12: 26.

16. Hogan E, Almira-Suarez I, Li S, Collins SP, Jean WC (2019) Clinical management of prostate cancer metastasis to pineal gland: case report and review of literature. World Neurosurg 122: 464-468.

17. Hadi A, Ghaedi E, Moradi S, Pourmasoumi M, Ghavami A, et al. (2019) Effects of melatonin supplementation on blood pressure: a systematic review and meta-analysis of randomized controlled trials. Horm Metab Res 51: 157164.

18. Bastos MAV Jr, Oliveira Bastos PRH, Portella RB, Soares LFG, Conde RB, et al. (2019) Pineal gland and schizophrenia: A systematic review and metaanalysis. Psychoneuroendocrinology 104: 100-114.

19. Takahashi T, Nakamura M, Sasabayashi D, Nishikawa $Y$, Takayanagi $Y$, et al. (2018) Reduced pineal gland volume across the stages of schizophrenia. Schizophr Res pp: 163-170.

20. Dantas-Ferreira RF, Raingard H, Dumont S, Schuster-Klein C, GuardiolaLemaitre B, et al. (2018) Melatonin potentiates the effects of metformin on glucose metabolism and food intake in high-fat-fed rats. Endocrinol Diabetes Metab 1: e00039.

21. Uyanikgil Y, Cavusoglu T, Kılıc KD, Yigitturk G, Celik S, et al. (2017) Usefu effects of melatonin in peripheral nerve injury and development of the nervous system. J Brachial Plex Peripher Nerve Inj 12: e1-e6.

22. Chen Y, Wu Y, Shi H, Wang J, Zheng Z, et al. (2019) Melatonin ameliorates intervertebral disc degeneration via the potential mechanisms of mitophagy induction and apoptosis inhibition. J Cell Mol Med 23: 2136-2148.

23. Alini M, Eisenstein SM, Ito K, Little C, Kettler AA, et al. (2008) Are animal models useful for studying human disc disorders/degeneration? Eur Spine J 17: 2-19.

24. Turgut M, Başaloğlu HK, Yenisey C, Özsunar Y (2006) Surgical pinealectomy accelerates intervertebral disc degeneration process in chicken. Eur Spine J 15: $605-612$

25. Uyanikgil Y, Cetin EO, Turgut M (2016) Effects of melatonin upon vascularity of cartilage end plate of intervertebral disc. J Spine 5: e123.

26. Liu H, Liu Z, Chi-wai M, Guo J, Han X, et al. (2019) The effect of exogenous melatonin on reducing scoliotic curvature and improving bone quality in melatonin-deficient C57BL/6J mice. Sci Rep 9: 6202.

27. Tsai SC (2017) Chronic obstructive pulmonary disease and sleep related disorders. Current Opinion in Pulmonary Medicine 23: 124-128.

28. Erland LA, Saxena PK (2017) Melatonin natural health products and supplements: presence of serotonin and significant variability of melatonin content. J Clin Sleep Med 13: 275-281. 